\title{
The transition from hospital to primary care for patients with acute coronary syndrome: insights from registry data
}

\section{Julie Redfern PhD, BAppSc(Hons), BSc Head, Public Health and Health Services Program ${ }^{7}$ \\ Tom G Briffa \\ Research Associate Professor and Head, Cardiovascular Research Group ${ }^{2}$ \\ 1 Cardiovascular Division, The George Institute for Global Health, Sydney, NSW. 2 School of Population Health, University of Western Australia, Perth, WA. \\ jredfern@ georgeinstitute.org.au}

doi: 10.5694/mjal4.01156 n Australia, acute coronary syndrome (ACS) accounts for about 75000 hospital separations annually, and in 2010 cost more than $\$ 8$ billion. ${ }^{1}$ Those who survive are at high risk of recurrent events; in 2010, more than 25000 Australian hospital separations were associated with repeat $\mathrm{ACS}^{2,3}$ at a cost of more than $\$ 600$ million (direct costs only). ${ }^{1}$ Between 2000-01 and 2008-09, the largest expenditure increase, by health care sector, was for hospital-admitted patient services, where cardiovascular disease expenditure increased by 55\%, from $\$ 2907$ million to $\$ 4518$ million. ${ }^{4} \mathrm{~A}$ recent report projected that by 2020 there will be around 102363 separations associated with ACS in Australia, and about half of these will be due to repeat events. ${ }^{1}$ These statistics highlight the growing importance of secondary prevention as more people survive initial events. Further, it underscores the need for a health system that has an inbuilt process for commencing prevention during acute admissions, and the need to ensure an effective transition from hospital to primary care.

Favourable modification of coronary risk factors is responsible for at least a $50 \%$ reduction in mortality from cardiovascular disease. ${ }^{5,6}$ Further, participation in secondary prevention programs leads to improved clinical, behavioural and health service outcomes, including fewer hospital readmissions, better adherence to pharmacotherapy, enhanced functional status, improved risk profile, less depression, and better quality of life..$^{-9}$ However, only a minority participate, ${ }^{10}$ systematic followup is fragmented, ${ }^{11}$ and questions remain about how well the health system facilitates transition from hospital to primary care. Overall, with ACS dominating expenditure and gaps in secondary prevention widely documented, addressing the delivery of care at the point of hospital discharge is a priority.

Modern cardiology has seen significant advancements in diagnosis, revascularisation, pharmacotherapy and overall more successful treatment of acute illness. ${ }^{12}$ This ultimately means that more people are surviving their initial ACS event and are having shorter hospital stays, which has resulted in more people returning to the community and resuming their everyday lives. ${ }^{13}$ However, one-quarter of survivors will be readmitted to hospital within 1 year of the index event, and a significant number of readmissions will end in death. ${ }^{2,3}$ Consequently, the demand for effective, continuing post-hospital preventive care is intensifying; the foundations of this are built during the acute episode. ${ }^{14}$

The purpose of this article is to provide insights from registries, and their implications for secondary prevention in Australia.

\begin{abstract}
Summary
Despite guidelines advocating routine engagement with proven secondary prevention strategies, current uptake and access remain suboptimal.

Australian registries of acute coronary syndrome have predominantly focused on inpatient care and have highlighted under-referral to cardiac rehabilitation, gaps in medication prescription and limited commencement of lifestyle change before discharge from hospital.

Opportunities to improve equity, access and uptake of secondary prevention include better transition between acute and primary care, systematic delivery of prevention in primary care, workforce strengthening and embracing new technologies.

Adopting a structured framework for delivery of secondary prevention in primary care will enhance continuity of care and improve coordination of services after acute coronary syndrome.
\end{abstract}

\section{Gaps in secondary prevention: data from Australian ACS registries}

Three large-scale Australian ACS registries - namely, SNAPSHOT ACS, the Cooperative National Registry of Acute Coronary care, Guideline Adherence and Clinical Events (CONCORDANCE) and the Acute Coronary Syndrome Prospective Audit (ACACIA) registry - have provided contemporary data about secondary prevention and resource gaps.

The SNAPSHOT ACS audit provides recent data pertaining to pre- and inhospital ACS care in Australia and New Zealand. ${ }^{12}$ The audit involved the collection of detailed information about 4398 consecutive patients admitted to 483 public and private hospitals across the two countries over 2 weeks in May 2012. ${ }^{12}$ The ACACIA registry enrolled 3402 ACS patients from 39 hospitals across Australia (25\% rural, 75\% metropolitan). ${ }^{3}$ CONCORDANCE is an ongoing (prospective) clinical initiative that provides continuous real-time reporting on the clinical characteristics, management and outcomes of hospitalised ACS patients to clinicians, hospital administrators, sponsors, interested stakeholders and government. ${ }^{15}$ CONCORDANCE currently includes about 5200 patients from more than 40 hospitals.

As a group, the Australian ACS registries provide detailed and contemporary information about inhospital care. All three registries show suboptimal rates of pharmacotherapy and cardiac rehabilitation referral. The proportion of patients prescribed at least four of the five indicated pharmacotherapies at discharge was $68 \%$ in CONCORDANCE ${ }^{16}$ and $65 \%$ in SNAPSHOT ACS. ${ }^{12}$ In terms of cardiac rehabilitation, $58 \%$ were referred in CONCORDANCE ${ }^{17}$ and $46 \%$ in SNAPSHOT ACS. ${ }^{12}$ 
A recent article resulting from SNAPSHOT ACS reported that only $27 \%(628 / 2299)$ of Australian and New Zealand patients admitted to hospital for ACS received a combination of guideline-recommended medications, referral to rehabilitation and basic lifestyle advice before hospital discharge. ${ }^{11}$ The authors suggested that a greater focus on inhospital delivery of preventive care is needed to provide the essential foundation for lifelong secondary prevention. $^{11}$

However, it should also be noted that registries have limitations, such as the reliance on inhospital documentation, and they may not be able to determine individual contraindications.

\section{The challenges in implementation of secondary prevention}

There are well known limitations in the implementation of secondary prevention after ACS. Despite proven effectiveness and clear recommendations in best-practice guidelines, ${ }^{18}$ there is poor use of effective medications, cardiac rehabilitation and adherence to lifestyle recommendations. ${ }^{19}$ In the recent AusHEART survey of more than 5000 Australian general practice patients, 1548 had clinically expressed cardiovascular disease, and only half of these were following recommended treatments. ${ }^{20}$ Valid national data on participation in cardiac rehabilitation and exercise therapy are not available, but estimates from local and international reports indicate that less than $30 \%$ of eligible patients participate in such programs. ${ }^{10,21}$ Compliance with lifestyle change is no better. It was recently reported that among 18809 patients from 41 countries who had experienced ACS, only $30 \%$ of patients adhered to diet and exercise recommendations, and about two-thirds of smokers had quit smoking 6 months after their event. ${ }^{22}$

Overall, it is difficult for a coherent strategy to emerge when the volume of evidence describing and reporting disparate models of delivery continues to expand..$^{13}$ In reality, about $70 \%$ of Australian secondary prevention programs continue to follow the traditional cardiac rehabilitation model of structured and group-based exercise with education sessions. ${ }^{19}$ These programs are associated with well documented barriers, including the need for transport, poor health provider support, limited time frames and minimal individualisation. Thus, policymakers, health professionals and researchers are confronted by the need for increased services to improve access and equity, but often with significant challenges coupled with finite and declining resources. ${ }^{13}$

\section{Opportunities for improved access to and} uptake of secondary prevention

A recent blueprint for reform summarises the outcomes of a national summit that aimed to improve implementation of secondary prevention in Australia. ${ }^{23}$ The report identifies stakeholder consensus for an approach where each patient's acute episode of care, particularly at discharge and follow-up, is patient-centred. The report also highlights the current challenges associated with the existence of a divide between hospital and general practice care. That divide is apparent in terms of a definition of prevention and rehabilitation, patient communication, service provision, funding and data collection. The summit report also summarises opportunities for improved implementation of secondary prevention. ${ }^{23}$ Although not exhaustive, the published opportunities present practical suggestions that cover a range of issues, including public health support, better coordination and use of existing strategies, workforce, quality assurance and technology, as follows:

- Increased delivery of comprehensive secondary prevention in primary care

$>$ Provision of connected care through a case-management approach, improved communication, and greater provider education relating to secondary prevention, behaviour change techniques and selfmanagement strategies.

$>$ This model of care should be coupled with specific incentive programs similar to those already available for diabetes and asthma management.

> Possible development of a role for cardiac care coordinators, who would ideally be recognised by Medicare. These coordinators could collaborate with the person with ACS and other members of the care team to achieve mutually agreed clinical targets, good health and wellbeing.

- Increased focus on and awareness of the need for lifelong secondary prevention

$>$ Potential for widespread media and public awareness campaigns to raise the profile and understanding of ACS as a chronic condition requiring lifelong management.

$>$ Requires linking with and engagement of state and federal governments, Medicare Locals, consumers and private health funds to facilitate sustainability.

- Better integration and use of existing services

Better use of existing initiatives, such as cardiac rehabilitation, chronic disease management plans, private health insurance programs, and other initiatives including the Home Medicines Review, Heart Foundation programs (eg, Heartmoves) and Quitline.

$>$ Better use and awareness of these existing programs may require development of a comprehensive inventory, database or website, and could be the domain of a national preventive agency, ideally in collaboration with state governments, Medicare Locals and non-government organisations, but could otherwise be housed by an established nongovernment organisation such as the National Heart Foundation.

- Data monitoring and quality assurance

$>$ Identification of performance measures to enable cross-national comparison is needed for post-hospital care. This should incorporate measures of service delivery as well as health outcomes, including hospital readmissions and coronary heart disease deaths.

> This could occur via an online registry and/or electronic medical records and data linkage. 


\section{- Embracing new technologies}

$>$ New technological developments have seen a rapid rise in devices and trials aimed at managing cardiovascular disease risk factors, medication adherence and providing coordinated care.

$>$ Ongoing development and testing of technological advances may facilitate greater access to secondary prevention.

> Examples of e-health approaches include the use of text messaging, telephone-delivered care, development of websites and smartphone apps and remote monitoring and remote delivery of programs.

\section{The increasing role of primary care in ACS management}

ACS requires lifelong management, and primary care is ideally positioned to provide this care to patients. ${ }^{23}$ There is a need to go beyond giving patients a discharge summary and advising them to make an appointment. In one study, about $20 \%$ of patients did not have a discharge summary forwarded to their general practitioner, and $68 \%$ of GPs rated the information in the summaries they received as "very good" to "excellent". ${ }^{24}$

In Australia, there has been a substantial shift in the payment system for GPs towards incentives that encourage evidence-based care of patients with chronic diseases in line with a disease management framework that emphasises systematic, coordinated care and selfmanagement. The Australian Government's commitment to a National Primary Health Care Strategic Framework provides an opportunity to establish primary care systems and funding models to enable people who are at high risk of a cardiovascular event to be identified early for preventive care. ${ }^{25}$ The National Heart Foundation maintains that a well developed primary care framework for secondary prevention will increase referral and access rates to secondary prevention services, enhance continuity of care and improve coordination of services between hospitals and the community. ${ }^{26}$

\section{Conclusion}

Despite guideline advocacy, uptake of proven secondary prevention strategies for heart disease is suboptimal. Australian registries provide contemporary data that reinforce the evidence-practice gaps in secondary prevention. Trial and cohort data highlight the need to commence prevention early if we are to narrow the divide between hospital and the community, thereby achieving better individual, provider and system-level outcomes. Patients often leave hospital without systematic followup and with an unclear picture of how and if they will be managed and supported on the next phase of their chronic disease journey. Potential opportunities to bridge the divide include development of an incentive scheme in primary care, development of a cardiac care coordinator role to work in concert with treating doctors and patients, better use of existing services, effective data monitoring and embracing new technologies.
Acknowledgements: Julie Redfern is funded by a Career Development and Future Leader Fellowship co-funded by the National Health and Medical Research Council and the National Heart Foundation (APP1061793).

Competing interests: The George Institute has received funding from AstraZeneca for research projects not directly linked with this manuscript.

Provenance: Commissioned; externally peer reviewed.

1 Deloitte Access Economics. ACS in perspective: the importance of secondary prevention. Canberra: Deloitte Access Economics, 2011. http://www.deloitte.com/assets/Dcom-Australia/Local\%20Assets/ Documents/Industries/Government\%20Services/Public\%20Sector/Deloitte_Acute_coronary_ syndrome_Nov2011.pdf (accessed Oct 2014).

2 Briffa TG, Hobbs MS, Tonkin A, et al. Population trends of current coronary heart disease event rates remain high. Circ Cardiovasc Qual Outcomes 2011; 4: 107-113.

3 Chew DP, Amerena JV, Coverdale SG, et al. Invasive management and late clinical outcomes in contemporary Australian management of acute coronary syndromes: observations from the ACACIA registry. Med J Aust 2008; 188: 691-697.

4 Australian Institute of Health and Welfare. Health expenditure Australia 2011-12: analysis by sector. Canberra: AlHW, 2014. (AlHW Cat. No. HWE 60; Health and Welfare Expenditure Series No. 51.) http://www.aihw.gov.au/publication-detail/?id=60129546642 (accessed Oct 2014).

5 Ford ES, Ajani UA, Croft JB, et al. Explaining the decrease in US deaths from coronary disease, 19802000. NEngl J Med 2007; 356: 2388-2398.

6 Unal B, Critchley JA, Capewell S. Explaining the decline in coronary heart disease mortality in England and Wales between 1981 and 2000. Circulation 2004; 109: 1101-1107.

7 Wenger NK. Current status of cardiac rehabilitation. J Am Coll Cardiol 2008; 51: 1619-1631.

8 Taylor RS, Brown A, Ebrahim S, et al. Exercise-based rehabilitation for patients with coronary heart disease: systematic review and meta-analysis of randomized controlled trials. Am J Med 2004; 116 : 682-692.

9 Clark AM, Hartling L, Vandermeer B, McAlister FA. Meta-analysis: secondary prevention program for patients with coronary artery disease. Ann Intern Med 2005; 143: 659-672.

10 Scott IA, Lindsay KA, Harden HE. Utilisation of outpatient cardiac rehabilitation in Queensland. Med J Aust 2003; 179: 341-345.

11 Redfern J, Hyun K, Chew DP, et al. Prescription of secondary prevention medications, lifestyle advice, and referral to rehabilitation among acute coronary syndrome inpatients: results from a large prospective audit in Australia and New Zealand. Heart 2014; 100: 1281-1288.

12 Chew DP, French J, Briffa TG, et al. Acute coronary syndrome care across Australia and New Zealand: the SNAPSHOT ACS study. Med J Aust 2013; 199: 185-191.

13 Redfern J, Maiorana A, Neubeck L, et al. Achieving coordinated secondary prevention of coronary heart disease for all in need (SPAN). Int J Cardiol 2011; 146: 1-3.

14 Brieger DB, Redfern J. Contemporary themes in acute coronary syndrome management: from acute illness to secondary prevention. Med J Aust 2013; 199: 174-178.

15 Aliprandi-Costa B, Ranasinghe I, Turnbull F, et al. The design and rationale of the Australian Cooperative National Registry of Acute Coronary care, Guideline Adherence and Clinical Events (CONCORDANCE). Heart Lung Circ 2013; 22: 533-541.

16 Chow C, Ranasinghe I, Blenkhorn A, et al. Use of secondary prevention medications in patients following admission with acute coronary syndrome in Australia - the CONCORDANCE study. Heart Lung Circ 2012; 21 Suppl 1: $\$ 264$.

17 Briffa T, Ranasinghe I, Ferry C, et al. Discordant uptake of cardiac rehabilitation in the CONCORDANCE hospitals. Heart Lung Circ 2012; 21 Suppl 1: S308.

18 National Heart Foundation of Australia, Cardiac Society of Australia and New Zealand. Reducing risk in heart disease: an expert guide to clinical practice for secondary prevention of coronary heart disease. Melbourne, NHFA, 2012. http://www.heartfoundation.org.au/SiteCollectionDocuments/Reducing-riskin-heart-disease.pdf (accessed Feb 2013).

19 Briffa TG, Kinsman L, Maiorana AJ, et al. An integrated and coordinated approach to preventing recurrent coronary heart disease events in Australia. Med J Aust 2009; 190: 683-686.

20 Heeley EL, Peiris DP, Patel AA, et al. Cardiovascular risk perception and evidence-practice gaps in Australian general practice (the AusHEART study). Med J Aust 2010; 192: 254-259.

21 Bethell HJ, Turner SC, Evans JA, Rose L. Cardiac rehabilitation in the United Kingdom. How complete is the provision? J Cardiopulm Rehabil 2001; 21: 111-115.

22 Chow CK, Jolly S, Rao-Melacini P, et al. Association of diet, exercise, and smoking modification with risk of early cardiovascular events after acute coronary syndromes. Circulation 2010; 121: 750-758.

23 Redfern J, Chow CK; Executive Committee and participants in the National Secondary Prevention of Coronary Disease Summit, 2011. Secondary prevention of coronary heart disease in Australia: a blueprint for reform. Med J Aust 2013; 198: 70-71.

24 Peterson GM, Thompson A, Pulver LK, et al. Management of acute coronary syndromes at hospital discharge: do targeted educational interventions improve practice quality? J Healthc Qual 2012; 34 : 26-34.

25 Australian Government Department of Health and Ageing. Primary health care reform in Australia: report to support Australia's first national primary health care strategy. Canberra: Commonwealth of Australia, 2009. http://apo.org.au/files/Resource/nphc-supp.pdf (accessed Oct 2014).

26 National Heart Foundation of Australia. Secondary prevention of cardiovascular disease: a call to action to improve the health of Australians. Melbourne: NHFA, 2010. http://www.heartfoundation.org.au/ SiteCollectionDocuments/Secondary-Prevention-of-cardiovascular-disease.pdf (accessed Feb 2014). $\square$ 